\title{
Mediating Effect of Social Media on the Consumer Buying Behavior of Cosmetic Products
}

\author{
Kabiru Jinjiri Ringim ${ }^{1}$ and Andi Reni ${ }^{2}$ \\ ${ }^{1}$ Universiti Teknologi Brunei, Brunei Darussalam, e-mail: kabiru.ringim@utb.edu.bn \\ ${ }^{2}$ Hasanuddin University, Indonesia, e-mail: andirenireni@gmail.com
}

\begin{abstract}
Social media are increasingly influencing and changing the way consumers behave, and how they make the decision to buy the cosmetics online via Facebook, Instagram, WhatsApp, and telegrams. The importance of cosmetics has increased, as many people want to stay young and look attractive. Therefore, the purpose of this study was to investigate the mediating effect of social media on the consumer behavior and intention to purchase the cosmetic product in Brunei Darussalam based on Theory of planned behavior (TPB). Consumer behavior is determined by the individual's intention to perform the behavior, intention is determined by attitudes toward the behavior, which are informed by beliefs needed to engage in the behavior; subjective norm, the social pressures to perform or not to perform the behavior and perceived behavioral control refers to people's perceptions of their ability to perform a given behavior. The study adopted a descriptive research design in form of crosssectional and survey in nature. A sample size of one hundred and eighty-seven (187) respondents drawn from Brunei Muara district of Brunei Darussalam. Stratified random sampling was used as all the respondents were drawn from different levels or strata within the district. Structured questionnaires were used for data collection with help of Personal Research Assistant as they were easy to administer and cheap in terms of cost and time by hand delivery. Data was collected and analyzed by use of Structural Equation Modelling - Smart Partial Least Square SEM - PLS. The reliability, content validity, discriminant validity and convergent validity are determined from the measurement model while structural model assessment, was done to test the significance of path coefficients for hypothesis testing of direct and indirect relationships. The results of the findings revealed that there is a strong significant positive impact on attitude, subjective norm and perceived behavioral control on consumer intention/buying behavior to purchase cosmetic products. Also, the social media has a significant positive mediating effect on consumer behavior and intention to purchase the cosmetic product in Brunei Darussalam. The conclusion of the findings was that the cosmetic products quality, price, friends, and acquaintances are important factors that will change the consumer behavior unexpectedly. Based on the findings, the results stated that the consumer buying behavior on cosmetic products through social media can be predicted by attitude, subjective norm and perceived behavioral control. The study made a recommendation and suggestion for future research.

Keywords: Consumer Behavior, Intention to purchase, Theory of Planned Behavior, Social Media, Cosmetic Product, Brunei Darussalam
\end{abstract}

\section{Introduction}

Today's technology of social networking sites has become a path where businesses can extend their marketing campaigns to a wider range of consumers. Social Media marketing is a connection between brands and consumers, by offering a personal channel and currency for user cantered networking and social interaction via digitization of the channel of business transaction (Chi, 2011). The digitization platform has changed consumer dynamics and consumption behaviors by increasing the role of the internet in daily life towards the emerging market and changing customer behaviors (Chi, 2011). Companies facing the challenge of customer attraction and retention are searching for the best predicting factors that lead to actual purchases on the social media internet platform (Hoffman \& Novak, 2000). The social media are increasingly influencing and changing the way the consumers behave, and how they make the decision to buy. Online businesses have become very popular due to 
the growing usage of internet in the social media such as Facebook, Instagram as well as the most popular social messaging apps globally (WhatsApp, WeChat, Line, Viber, Blackberry Messenger, Telegram, and Kakaotalk).

Brunei Darussalam has the third highest social media penetration in the world with 370,000 users, or $86 \%$ of the total population (New Digital, 2017). Global Overview reported that Brunei Darussalam has fared very high in terms of penetration of mobile social media with $76 \%$ using it, and is the sixth highest globally after Qatar, the UAE, South Korea, Aruba and Maldives (Bandial, 2016). Statistics by Statcounter, (2015) argued that $56.8 \%$ of Bruneian uses Facebook and $2.19 \%$ uses Instagram. The report further argued that most of the social network users in Brunei Darussalam use Facebook with the usage of about $97.4 \%$. Twitter ranks second with $1.1 \%$, Pinterest ranks third with $0.88 \%$, Tumblr ranks fourth with $0.34 \%$ and the remaining social networks holds $0.28 \%$ using Mobile internet (Statcounter, 2015). Social media platform utilization in Brunei Darussalam has also become more popular and play an important part in communication in the Household (ICT Survey, 2016). The top three social networking websites used in Brunei Darussalam are Facebook, Instagram, and Twitter. From a business perspective, there has been an increase in businesses, buyers and sellers interaction via social media. The marketing activities of buying and selling of the cosmetics products on social media platform have been on increase over a period of time (Parson, 2013). Therefore, the consumer intention to buy cosmetics products online is high as a result of the acceptability of social media platform usage in Brunei Darussalam.

The Authority that regulates the activities of cosmetics and drugs in Brunei Darussalam is the Medicines Control Authority (BDMCA). All importers or manufacturers must notify the Authority before placing the cosmetic product in the local market. Cosmetics are commonly referred to as personal care products. These include, for example, skin moisturizers, perfumes, lipsticks, fingernail polishes, eye and facial makeup preparations, shampoos, permanent waves, hair colours, toothpaste, and deodorants. With the help of social media, businesses/sellers obtained an opportunity for the cheapest way to market their products such as the personal care product whose demand was on increase in Brunei Darussalam. BDMCA has classified cosmetic products into three (3) categories (high, medium, and low risk) in Brunei Darussalam. The cosmetics products are being imported and sold both through online social media platform and at the physical shop location in Brunei Darussalam. Risky cosmetic products category which is manufactured with a sub-standard product and contains prohibited substances may have adverse effects after use, hence the cosmetics trading is highly regulated by the BDMCA. The cosmetics usually have the functions to enhance people's appearance as there has been an increased in many people that want to stay young and look attractive. Theory of planned behavior(TPB) postulated on the individual's intention to perform the behavior (Azjen, 1991). Hence, the intention is determined by three factors; attitudes toward the behavior, which are informed by beliefs needed to engage in the behavior; subjective norm are the social pressures to perform or not to perform the behavior, and perceived behavioral control refers to people's perceptions of their ability to perform a given behavior. The likelihood of forming behavioral intention leading to the performing of certain behavior is high when a person is fulfilling the variables by having a positive attitude, favorable social norms surrounding and high level of perceived behavioral control (Azjen, 1991). Specifically, the attitudes of consumers can have a significant effect on buying behavior and purchasing power decisions including the awareness of the consumers towards the adulterant found with undeclared substance in the cosmetics product, which can cause adverse effects that are potentially hazardous to the people's enthusiasm in the use of cosmetics, they were unaware that cosmetic can lead to danger to the body if there are any prohibited substances being used as their ingredients. This happens if they choose fake product instead of the original products. Thus, the objectives for this research are: To determine the effects of the consumer purchasing behavior of cosmetic products in Brunei based on the Theory of Planned Behavior (TPB), and to determine the mediating effect of social media marketing platform on the consumer buying behavior of cosmetics products in Brunei Darussalam. 
Consumer Behavior Intention. Theory of planned behavior (TPB) suggests that a person's behavior is determined by his/her intention to perform the behavior and that this intention is, in turn, a function of his/her attitude toward the behavior and his/her subjective norm (Ajzen, 1985; Ajzen, 1991). The pricing is one of the factors which can affect the consumer behavior in their buying decision. Evans et al. (1996, 270), has defined the price as the thing that a consumer will need to rethink whether or not (just give up) to buy that certain product. In addition to the specific amount that needed to pay for a product that they aimed for, there are also other costs involved which give effect the perception of price. These not only about pricing but also the matter of time, cognitive activity or elaboration, and the behavioral effort. Thus, there are four basic types of costs in total. The financial estimation of an item is frequently considered the principal cost. It might be detected contrary by various customers relying upon their salary level, individual spending plan and other statistic and psychorealistic factors. Most customers additionally figure the time as to use it to find out about a product or go to buy it and additional time spent in a store just to pick the correct items as being a part of the cost. By reduce the cost that involved in cognitive elaboration, it needs to use simple decision making in order to meet the wants. The last part of the cost is part of the product price that the consumer often calculating which is the behavioral effort to acquire it. This means the consumer needs to do the actual behavior and action by looking into the catalog to purchase the product.

Attitudes. Attitudes are informed by beliefs that needed to engage in the behavior (Azjen, 1991). It is defined as an individual's positive or negative feeling associated with performing a specific behavior". An individual will hold a favourable attitude toward a given behavior if he/she believes that the performance of the behavior will lead to mostly positive outcomes and benefits to themselves. Several past studies had found a significant direct relationship between attitude and internet purchasing (Celik, 2008; George, 2002, 2004; Chai and Pavlou, 2004). Celik (2008) found that attitude is significantly related to internet banking intention while Chai and Pavlou (2004) establish that attitude is a significant predictor of electronic commerce intention in two countries, Greece and USA. The buying behavior can be affected based on the attitude of the consumers. The effective component is the feeling part of attitudes and it captures either a positive or negative situation (Evans et al. 1996; Noel, 2009). The cognitive component covers the actions and behavioral intention of the consumers (Evans et al. (1996). The attitude is formed as a result of experience and learning outcomes and these factors did affect the consumer buying behavior (Kotler and Keller, 2009, 210). Attitudes may also be formed through feelings toward a product by experiencing it (Noel, 2009). Therefore, based on the review on previous studies on consumer's attitude toward behavioral intention, the study hypothesis that:

$\mathrm{H}_{\mathrm{A} 1}$ : Attitude has a positive significant effect on consumer behavioral intention to purchase the cosmetic product in Brunei Darussalam on the platform of social media.

Subjective Norms. Subjective norm is "the perceived social pressure to engage or not to engage in a behavior". It is assumed that subjective norm is determined by the total set of accessible normative belief concerning the expectations of important referents (Ajzen, 1991). Chai and Pavlou (2002) found subjective norms "to be significantly related to intention in both countries US and Greece". However, according to George (2002), internet purchasing is not part of the subjective norm. Subjective norm can be interpreted as personal motivation to obey with the expectations of people which is important to the individual such as peers and superiors ((Taylor \& Todd, 1995; Venkatesh, Morris \& Ackerman, 2000). More specifically, if the consumer believes that referents consider a particular product as good, the more likely would he/she intend to purchase the product (Kim \& Chung, 2011). Past studies such as Souiden and Diagne (2009), Sukato and Elsey (2009), argued that there is a positive correlation between the perception of subjective norm and behavioral intention to purchase skincare products. Therefore, based on the review on previous studies on consumer's subjective norms toward behavioral intention, the study hypothesis that:

$\mathrm{H}_{\mathrm{A} 2}$ : Subjective norm has a positive significant effect on consumer behavioral intention to purchase the cosmetic product in Brunei Darussalam on the platform of social media. 
Perceived Behavior Control. Perceived behavioral control "refers to people's perceptions of their ability to perform a given behavior. Azjen compares perceived behavioral control to Bandura's concept of perceived self-efficacy" (Bandura, 1997). TPB also includes a direct link between perceived behavioral control and behavioral achievement. Drawing an analogy to the expectancyvalue model of attitude, it is assumed that perceived behavioral control is determined by the total set of accessible control belief, i.e., beliefs about the presence of factors that may facilitate or impede the performance of the behavior. To the extent that it is an accurate reflection that perceived behavioral control can, together with intention, be used to predict behavior. Past studies have found inconsistent findings as regards to the relationship of perceived behavior control and intention (Chai and Pavlou, 2004; George, 2004). In the most occasion, perceived behavior control is not a significant predictor of intention or behavior. According to the study conducted by Oakley (2009), women wearing cosmetic feel more confident due to these brands advertise them as providing the confidence that needs to be shown in the society. Therefore, based on the review on previous studies on consumer's perceived behavioral control and behavioral intention, hence, the study hypothesis that:

$\mathrm{H}_{\mathrm{A} 3}$ : Perceived behavioral control has a positive significant effect on consumer behavioral intention to purchase the cosmetic product in Brunei Darussalam on the platform of social media.

Social Media. A social media website first developed by Mark Zuckerberg while he was a student at Harvard in 2004. It is a series of websites and applications designed to allow people to share content quickly, efficiently and in real-time. The ability to share photos, opinions, events in real-time has transformed the way people do live and it is also transforming the way people do business. Previous studies argued that over 11 million consumers use more than $70 \%$ of many social media to do their shopping and purchasing of different products and services on the platform of social media (Miller and Lammas, 2010). The most popular social media platform that is mostly used by the consumers are Facebook, Twitter, and Instagram. Therefore, based on the review on previous studies on the perceived social media platform, consumer's attitude, subjective norms, and perceived behavioral control toward behavioral intention. Thus, the study hypothesis that:

$\mathrm{H}_{\mathrm{A} 4}$ : Social Media has a positive significant mediating effect on the consumer attitude and intention to purchase the cosmetic product in Brunei Darussalam.

$\mathrm{H}_{\mathrm{A} 5}$ : Social Media has a positive significant mediating effect on the consumer subjective norm and intention to purchase the cosmetic product in Brunei Darussalam.

$\mathrm{H}_{\mathrm{A} 6}$ : Social Media has a positive significant mediating effect on the consumer Perceived behavioral control and intention to purchase the cosmetic product in Brunei Darussalam.

Conceptual Framework and Underpinning Theories: Planned Behavior (TPB) \& Technology Acceptance Model (TAM). A theoretical basis that throws more light by explaining the relationship between attitude, subjective norm, perceived behavioral control and Intention to purchase cosmetics product drawn from the theory of planned behavior, developed by Ajzen in 1991. According to the theory, human action is guided by three kinds of beliefs: beliefs about the likely outcomes of the behavior and the evaluations of these outcomes (behavioral beliefs) which produce a favorable or unfavorable attitude toward the behavior; beliefs about the normative expectations of others and motivation to comply with these expectations (normative beliefs) result in perceived social pressure or subjective norm; and beliefs about the presence of factors that may facilitate or impede performance of the behavior and the perceived power of these factors (control beliefs) give rise to perceived behavioral control (Ajzen \& Fishbein, 1973). The combination of the three constructs i.e. attitude toward the behavior, subjective norm, and perception of behavioral control is assumed to lead to the formation of a behavioral intention to purchase cosmetic products. Purchase intention variable will access the strength of consumer intention to buy the cosmetic products in the future. The assumption of this study is that the more favorable the attitude, subjective norms, and behavioral control the more favorable the self-efficacy and the stronger would be the consumer intention to purchase the cosmetic products in the future as shown in Figure 1.0. 
The technology acceptance model (TAM) is an information systems theory that models how users come to accept and use a technology. The model suggests that when users are presented with a new technology, a number of factors influence their decision about how and when they will use it, notably: Perceived usefulness (PU) - This was defined by Fred Davis as "the degree to which a person believes that using a particular system would enhance his or her job performance". Perceived ease-of-use (PEOU) - Davis defined this as "the degree to which a person believes that using a particular system would be free from effort" (Davis 1989). On the other hand, according to Chi (2011), it is suggested that users' motivations for online social networking may play a vital role in defining consumer's responses to social media marketing and users usually perceive advertising differently. Harris and Dennis (2011) argued that the Technology Acceptance Model (TAM) as a loose framework that combined trust and the factors associated with TAM (i.e. usefulness, ease of use and perceived enjoyment). This framework determined that consumers specifically students hold a hierarchy of trust when using social media such as Facebook. They trust 'real' friends than their Facebook friend, followed by expert blogs, independent review sites and lastly celebrities and e-retailer's sites (Harris and Dennis 2011).

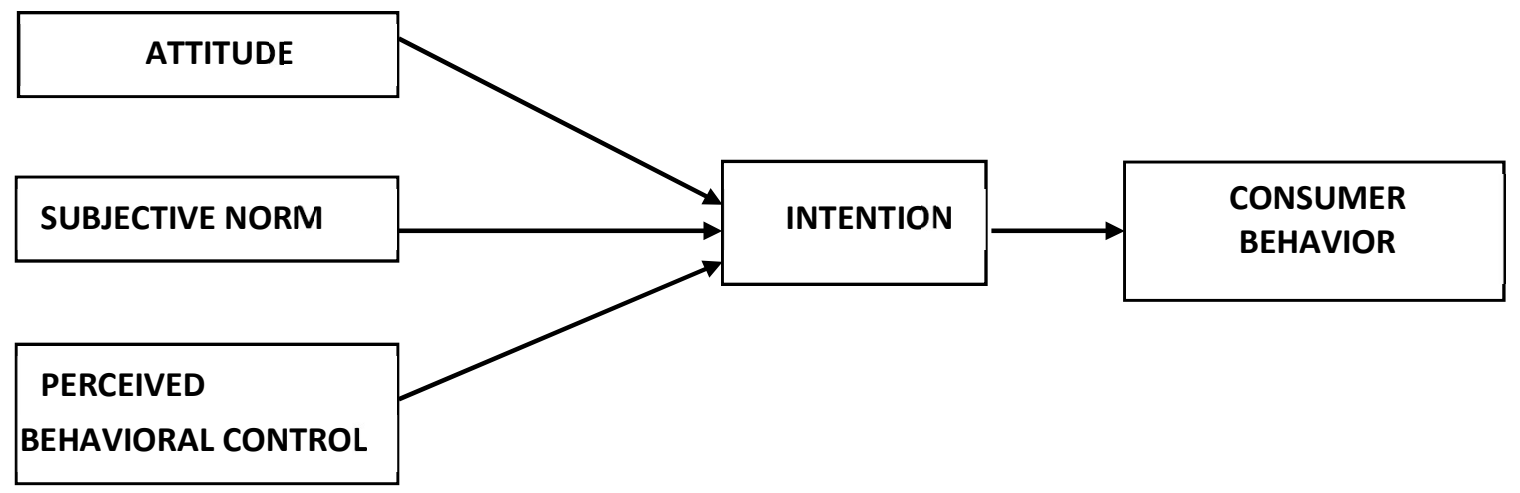

Figure 1. Theoretical Framework

In line with the assumptions of the two theories discussed above, the conceptual framework is formulated in Figure 2.0.

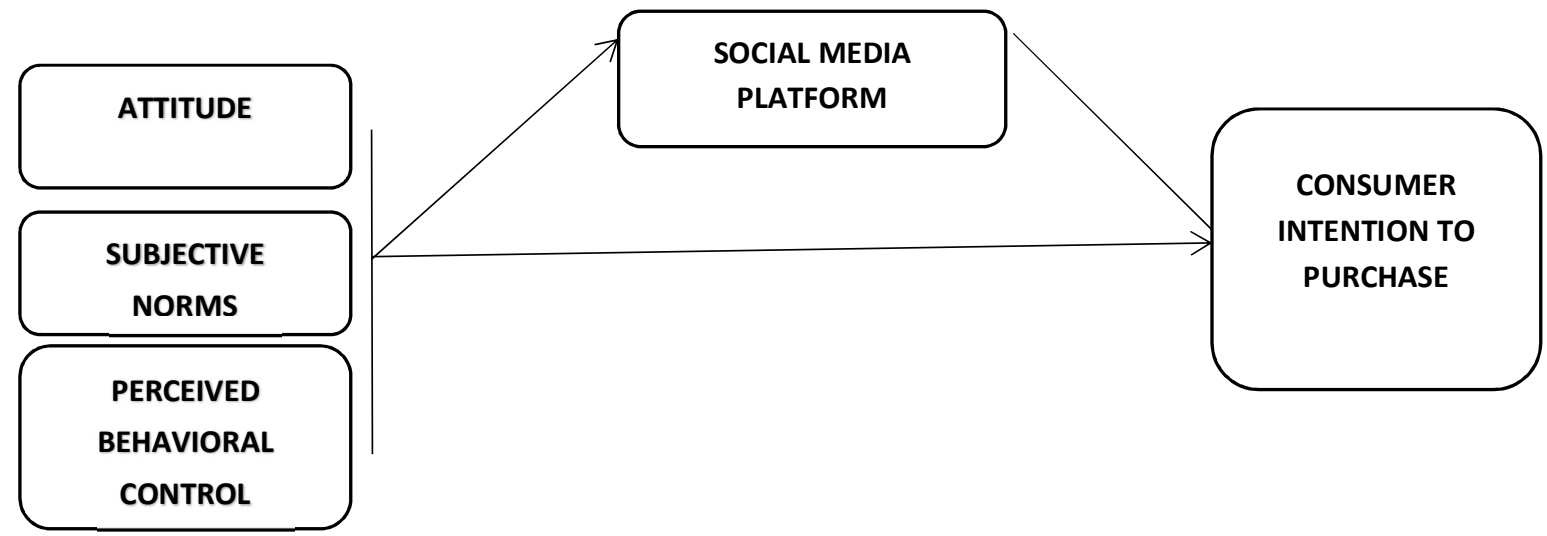

Figure 2. Conceptual Framework

Model Specification. The study employed the multiple regression models to test the effect of attitude, subjective norms and perceived behavioral control on consumer's intention to purchase cosmetics product in Brunei Darussalam. The Multiple regression models were also developed to test the hypotheses on the influence of the independent variables (attitude, subjective norms, and perceived 
behavioral control) on the dependent variable (consumer's intention to purchase). The regression model that captured the hypotheses of the study as thus presented:

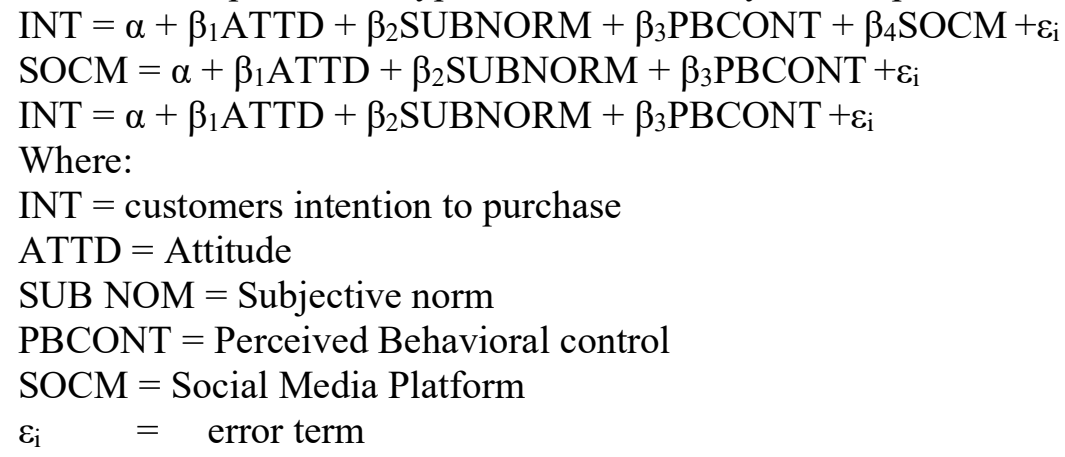

Decision Rule: The decision to accept or reject the alternate hypothesis $\left(\mathrm{H}_{\mathrm{A}}\right)$ of the statistical test was based on the $95 \%$ confidence level @ 0.05 margin of error. We reject the null hypothesis if the $\mathrm{P}$ value is at or less than the $5 \%(0.05)$ level of significance from the regression output.

\section{Research Methodology}

The study used a descriptive survey research design, cross-sectional in nature by collecting the data at a particular point in time and used the quantitative method of data analysis. The population for this study consists of a large population of about 370,000 users, or $86 \%$ of the total population of Bruneian that used social media (Digital in Global Overview report, 2017). Thus, using the table of sample size provided by Krejcie and Morgan (1970), a minimum sample size of 382 is required. However, to reduce sample size error and also to take care of the non-response problem, the questionnaires distribution was increased by $10 \%$ added to the above minimum sample size given by the formula to make it 420 . The addition of $10 \%$ to the sample size to also take care of other unavoidable errors such as incorrect filling and failure of some respondents to return questionnaire (Israel, 2013). Therefore, 420 questionnaires distributed to the respondents with the help of Research Assistant using personal self-administration and online distribution through WhatsApp, Facebook, and Instagram, 392 were adequately filled and returned by the respondents. The questionnaire was distributed and administered through Google Form, a web-based online survey in order to gain advantages such as lower costs, faster responses and geographically unrestricted sample (Ridings, Gefen \& Arinze, 2002).

A structured closed-ended questionnaire was adapted from previous studies with measurement scale of five-point Likert scale ranging from strongly agree (1), agree (2), Neutral (3), disagree (4) strongly disagree (5). Attitude questionnaire (6) six items were adapted from previous studies (Osman, Chan \& Bei, 2010; Sultan \& Uddin, 2001; Bhattacherjee, 2001; George, 2004; Ljubljana, 2015; Kim, 2004; Sentosa, Nik Kamariah Nik Mat, (2012). Subjective norm is defined as the perceived social pressure to engage or not to engage in a behavior measured by (3) three items adapted from the previous studies (Siitan, 2015; Johnson, 2015). Perceived behavioral control refers to people's perceptions of their ability to perform a given behavior. It has (4) four items on the questionnaire adapted from George (2004); Britton (2012); McGinn (2016). The intention to purchase is an indication of a person's readiness to perform a given behavior, and it is considered to be the immediate antecedent of behavior (Bagozzi, Baumgartner \& Yi 1998). The intention has (5) five items measurement scale adapted from Nyagucha (2017), Lindmark 2015, Liwei \& Chen, (2014). The social media platform is measured by Instagram and Facebook's online marketing activities such as celebrity endorsement, reviews by customers and bloggers and quality of pictures used are antecedents to an increase in the number of likes, followers, and shares in both social media (Fullerton, 2007; McDonald and Johnson, 2014). Expert in academic and professional practice had validated the questionnaire items. 


\section{Result and Discussion}

PLS-SEM Analysis Results. The study used a structural equation model, PLS path modeling in conjunction with Smart PLS 3.0 software to processed and analysed the data (Ringle, Wende \& Becker, 2015). The PLS path modelling was considered appropriate technique of data analysis because, it can simultaneously assess the measurement model, which describes the link between theory (latent constructs) and data (corresponding indicators) as well as relationships among constructs, also called the structural model (Hair, Hult, Ringle \& Sarstedt, 2017). Also, the goal of the present study is to predict the effect of Attitude, Subjective norms, Perceived behavioral control, and intention. Hence, the present study is causal-predictive where a complex model with many variables, indicators, and relations tested using path modeling approach (Hair, Hollingsworth, Randolph \& Chong, 2017; Hair, Hult, et al., 2017; Hair, Matthews, Matthews \& Sarstedt, 2017). Moreover, previous studies have recommended the use of PLS path modeling when the goal of the research is to predict the dependent variable. PLS path modelling used successfully in the past empirical studies related to consumer and marketing behavior research (e.g., Carraresi, Mamaqi, Albisu \& Banterle, 2016; Lechner \& Gudmundsson, 2014; Pratono \& Mahmood; Vlasov, Bahlmann \& Knoben, 2016).

Measurement model. In the present study, a measurement model evaluated for reliability and validity. Reliability and validity are two essential criteria for assessing the quality of measures (Andrew, Pedersen \& McEvoy, 2011; Kimberlin \& Winterstein, 2008). Reliability has been defined as the consistency or stability of measure each time it is administered (Hays \& Revicki, 2005). Reliability usually ascertained at the individual indicator level or a given construct level (Götz, Liehr-Gobbers \& Krafft, 2010; Im \& Grover, 2004). The measurement scales evaluated by individual item reliability, internal consistency reliability, convergent validity, as well as discriminant validity (Hair, Hollingsworth, et al., 2017; Hair, Hult, et al., 2017; Hair, Matthews, et al., 2017). The full Measurement model presented in Table 2.

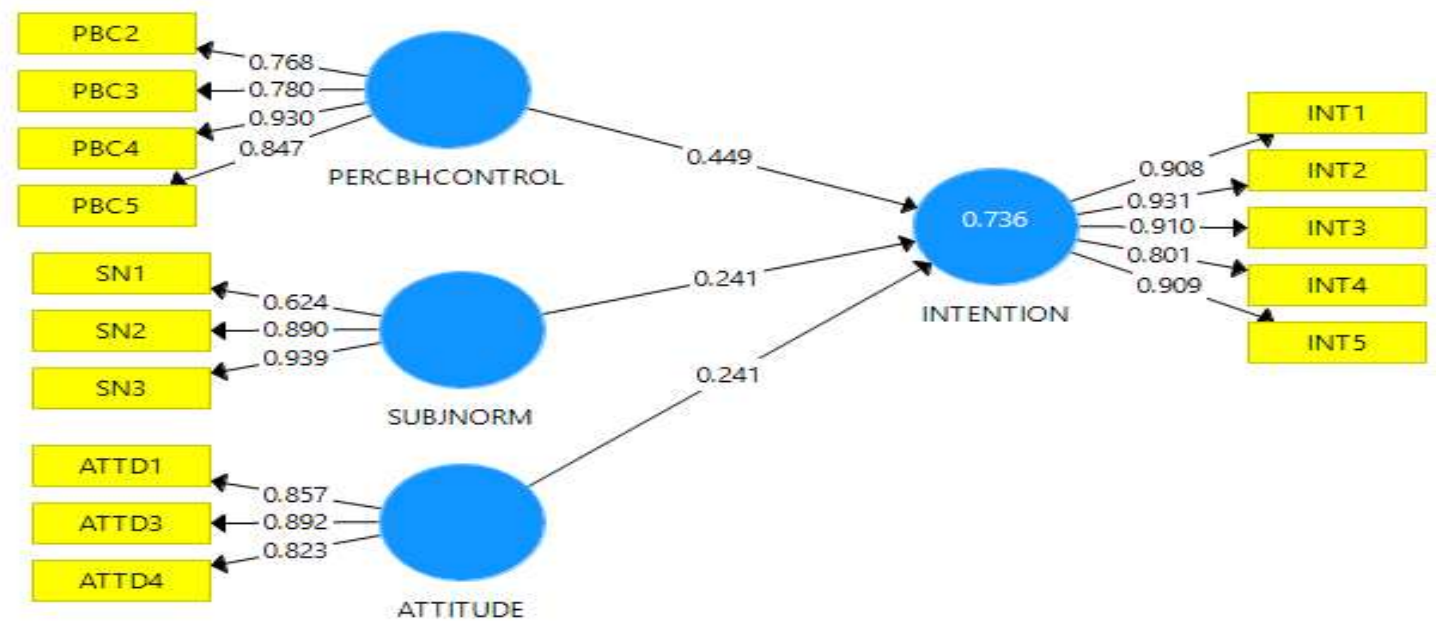

Figure 3. Structural Model: Direct effect 
Table 1. Measurement Model Results

\begin{tabular}{|c|c|c|c|c|c|c|c|}
\hline $\begin{array}{l}\text { Variables } \\
\text { items }\end{array}$ & \multicolumn{4}{|c|}{ FACTOR LOADINGS } & \multirow[b]{2}{*}{ rho_A } & \multirow[b]{2}{*}{$\mathrm{CR}$} & \multirow[b]{2}{*}{ AVE } \\
\hline & Attitude & Intention & $\begin{array}{l}\text { Behavior } \\
\text { control }\end{array}$ & $\begin{array}{l}\text { Subjective } \\
\text { norm }\end{array}$ & & & \\
\hline ATTD1 & 0.857 & & & & \multirow{3}{*}{0.895} & \multirow{3}{*}{0.893} & \multirow[t]{3}{*}{0.736} \\
\hline ATTD3 & 0.892 & & & & & & \\
\hline ATTD4 & 0.823 & & & & & & \\
\hline INT1 & & 0.908 & & & \multirow{5}{*}{0.954} & \multirow{5}{*}{0.952} & \multirow[t]{5}{*}{0.798} \\
\hline INT2 & & 0.931 & & & & & \\
\hline INT3 & & 0.910 & & & & & \\
\hline INT4 & & 0.801 & & & & & \\
\hline INT5 & & 0.909 & & & & & \\
\hline PBC2 & & & 0.768 & & \multirow{4}{*}{0.906} & \multirow{4}{*}{0.9022} & \multirow{4}{*}{0.695} \\
\hline PBC3 & & & 0.780 & & & & \\
\hline PBC4 & & & 0.930 & & & & \\
\hline PBC5 & & & 0.847 & & & & \\
\hline SN1 & & & & 0.624 & \multirow{3}{*}{0.894} & \multirow{3}{*}{0.862} & \multirow{3}{*}{0.688} \\
\hline SN2 & & & & 0.890 & & & \\
\hline SN3 & & & & 0.939 & & & \\
\hline
\end{tabular}

Validity and Reliability. We evaluated individual items reliabilities based on standardized loadings for each of the latent constructs (Hair, Hollingsworth, et al., 2017; Hair, Hult, et al., 2017; Hair, Matthews, et al., 2017). Reliability of an individual item confirmed when it's standardized loading to retained between 0.4 and 0.7 or higher (Bagozzi \& Yi, 1988; Hair et al., 2011). Inspection of standardized loadings for individual items suggested that items had loadings between 0.605 and 0.811as shown in Table 1. Thus, the retained elements in the measurement model were deemed reliable.

In this study, construct reliability was determined based on composite reliability coefficient (Hair, Hollingsworth, et al., 2017; Hair, Hult, et al., 2017; Hair, Matthews, et al., 2017). According to Hair, Ringle, and Sarstedt (2011), satisfactory construct reliability established when the composite reliability (CR) index of 0.70 or higher. Therefore, Table 2 showed that the composite reliability indices of all latent constructs were between 0.802 and .0 .838 . It suggests that satisfactory construct reliability achieved because the composite reliability indices reported in this present study were above the acceptable cut-off point of 0.70 .

The literature on PLS-SEM indicates that convergent validity is ascertained using the average variance extracted (Hair, Matthews, et al., 2017). To achieve adequate convergent validity, Fornell and Larcker (1981) recommended that AVE values should be 0.50 or higher. As indicated in Table 2, AVE values ranged between 0.505 and 0.513 , and all latent constructs demonstrate AVE values higher than the recommended threshold of 0.50 . Hence, it can be concluded that adequate convergent validity has been established in the present study. 
The present study also used Fornell-Larcker criterion approach to establish discriminant validity. Fornell-Larcker approach involves comparing the square root of AVEs with the correlations between constructs extracted (Hair, Matthews, et al., 2017). Additionally, adequate discriminant validity is achieved if, the diagonal elements are significantly higher than the off-diagonal elements in the corresponding rows and columns. The results of the discriminant validity analysis using FornellLarcker criterion reported in Table 2. Following Hair, Matthews et al. (2017), adequate discriminant validity has been established in the present study because the square root of AVEs was higher than the correlations between constructs.

Table 2. Results of Discriminant Validity Based on Fornell-Larcker Criterion

\begin{tabular}{|l|l|l|l|l|l|}
\hline \multicolumn{2}{|l|}{ Latent Construct } & 1 & 2 & 3 & 4 \\
\hline 1 & Attitude & $\mathbf{0 . 8 5 8}$ & & & \\
\hline $\begin{array}{l}\text { Perceived behavioral } \\
\text { control }\end{array}$ & 0.804 & $\mathbf{0 . 8 9 3}$ & & \\
\hline 3 & Subjective Norm & 0.815 & 0.809 & $\mathbf{0 . 8 3 4}$ & \\
\hline 4 & Purchase Intention & 0.818 & 0.743 & 0.680 & $\mathbf{0 . 8 2 9}$ \\
\hline
\end{tabular}

Note: "Diagonal elements are the square root of the variance shared between the constructs and their measures (AVE). Off-diagonal elements are the correlations among constructs".

Structural model. Following Hair, Hult et al. (2017) as well as Henseler, Ringle, and Sinkovics (2009), we applied bootstrapping with 5000 resamples to test the statistical significance of PLS-SEM results, including structural path coefficients, $R^{2}$ values, $f^{2}$ values and Heterotrait-Monotrait Ratio of Correlations (HTMT). The full results of a structural model that included the direct effect model, (baseline model) presented in Table 4 and Figures 2 clearly indicated that the relationship between Attitude, Perceived behavioral control, Subjective Norm and customer's Purchase Intention.

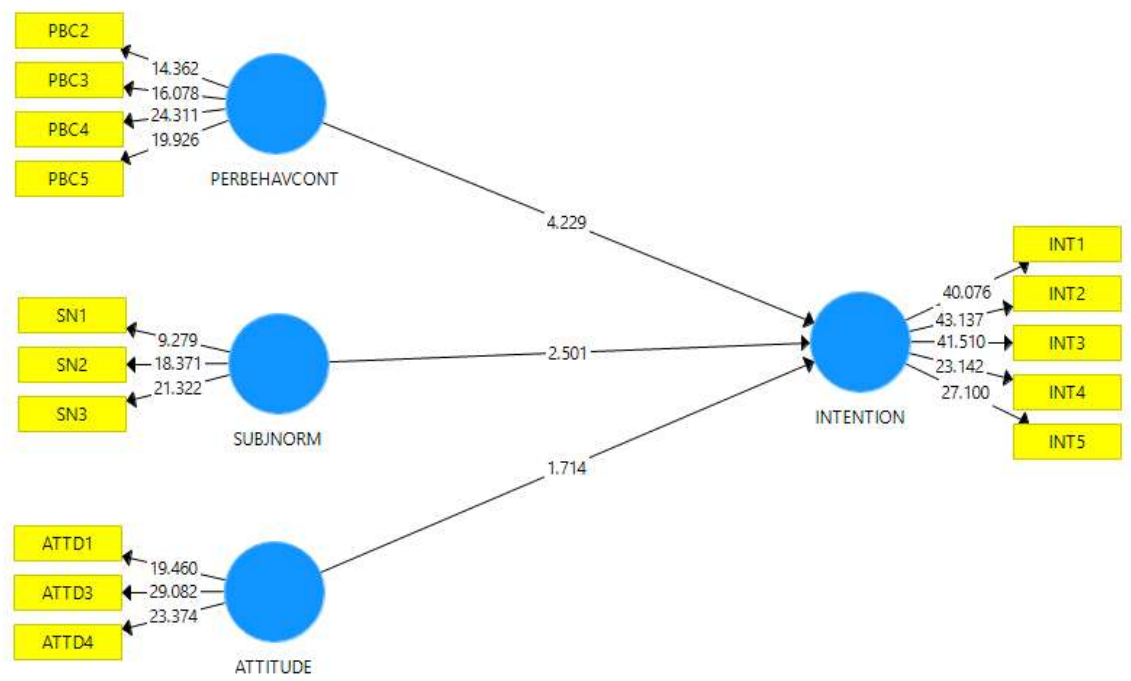

Figure 4. Structural Model: Direct effect 
Table 3. Structural Model Results - Direct effect

\begin{tabular}{|l|r|r|r|r|l|}
\hline \multicolumn{1}{|c|}{ Hypothesis } & $\beta$ & $\begin{array}{l}\text { Standard } \\
\text { Error } \\
\text { erro } \\
\text { error }\end{array}$ & $t$-Stat & $p$-Value & Findings \\
\hline ATTITUDE -> INTENTION & 0.241 & 0.140 & $1.714 * *$ & 0.043 & Supported \\
\hline $\begin{array}{l}\text { PERBEHAVCONT -> } \\
\text { INTENTION }\end{array}$ & 0.449 & 0.106 & $4.229 * * *$ & 0.000 & Supported \\
\hline SUBJNORM -> INTENTION & 0.241 & 0.096 & $2.501 * * *$ & 0.006 & Supported \\
\hline
\end{tabular}

Note: $* * *$ Significant at 0.01 (1-tailed).

As shown in Table 3, the hypotheses were supported, as Attitude significantly associated with purchase intention in the positive direction $(\beta=0.241, t=1.714, p<0.0043)$. The second Hypotheses examined the effect of perceived behavioral control positively significantly associate to customer purchase intention $(\beta=0.449, t=4.229, p<0.0000)$. The third Hypotheses examined the effect of subjective norms positively significantly associate to customer purchase intention $(\beta=0.241, t=$ 2.501, $p<0.0006)$.

Table 4. Structural Model Results - Indirect effect

\begin{tabular}{|l|c|r|r|r|l|}
\hline \multicolumn{1}{|c|}{ Hypothesis } & $\beta$ & $\begin{array}{c}\text { Standard Error } \\
\text { (STD error) }\end{array}$ & $t$ - Stat & $\begin{array}{c}\text { 95\% Confidence } \\
\text { Interval }\end{array}$ & Findings \\
\hline $\begin{array}{l}\text { ATTITUDE -> SOC -> } \\
\text { INTENTION }\end{array}$ & 0.110 & 0.073 & 1.509 & {$[0.005 ; 0.238]$} & Supported \\
\hline $\begin{array}{l}\text { PERBEHAVCONT -> SOC - } \\
>\text { INTENTION }\end{array}$ & 0.113 & 0.050 & 2.274 & {$[0.038 ; 0.200]$} & Supported \\
\hline $\begin{array}{l}\text { SUBJNORM -> SOC -> } \\
\text { INTENTION }\end{array}$ & 0.095 & 0.056 & 1.688 & {$[0.015 ; 0.196]$} & Supported \\
\hline
\end{tabular}

Note: $* * *$ Significant at 0.02 (1-tailed).

As demonstrated in Table 4, The results showed that social media plays a significant positive role in the relationship between consumer behavior (attitude, subjective norm, perceived behavior control) and intention to purchase the cosmetic product in Brunei Darussalam. Hypotheses examined the role of social media on the attitude positive significant association to customer purchase intention ( $\beta=$ $0.110, \mathrm{t}=1.509 @ 95 \%$ confidence interval of [0.005;0.238]. The second Hypotheses examined the role of social media on the perceived behavioral control positive significant association to customer purchase intention $(\beta=0.113, \mathrm{t}=2.274$, @ 95\% confidence interval of $[0.038 ; 0.200]$. The third Hypotheses examined the role of social media on the subjective norm positive significant association to customer purchase intention ( $\beta=0.095, \mathrm{t}=1.688,95 \%$ confidence interval of $[0.015 ; 0.196]$. 


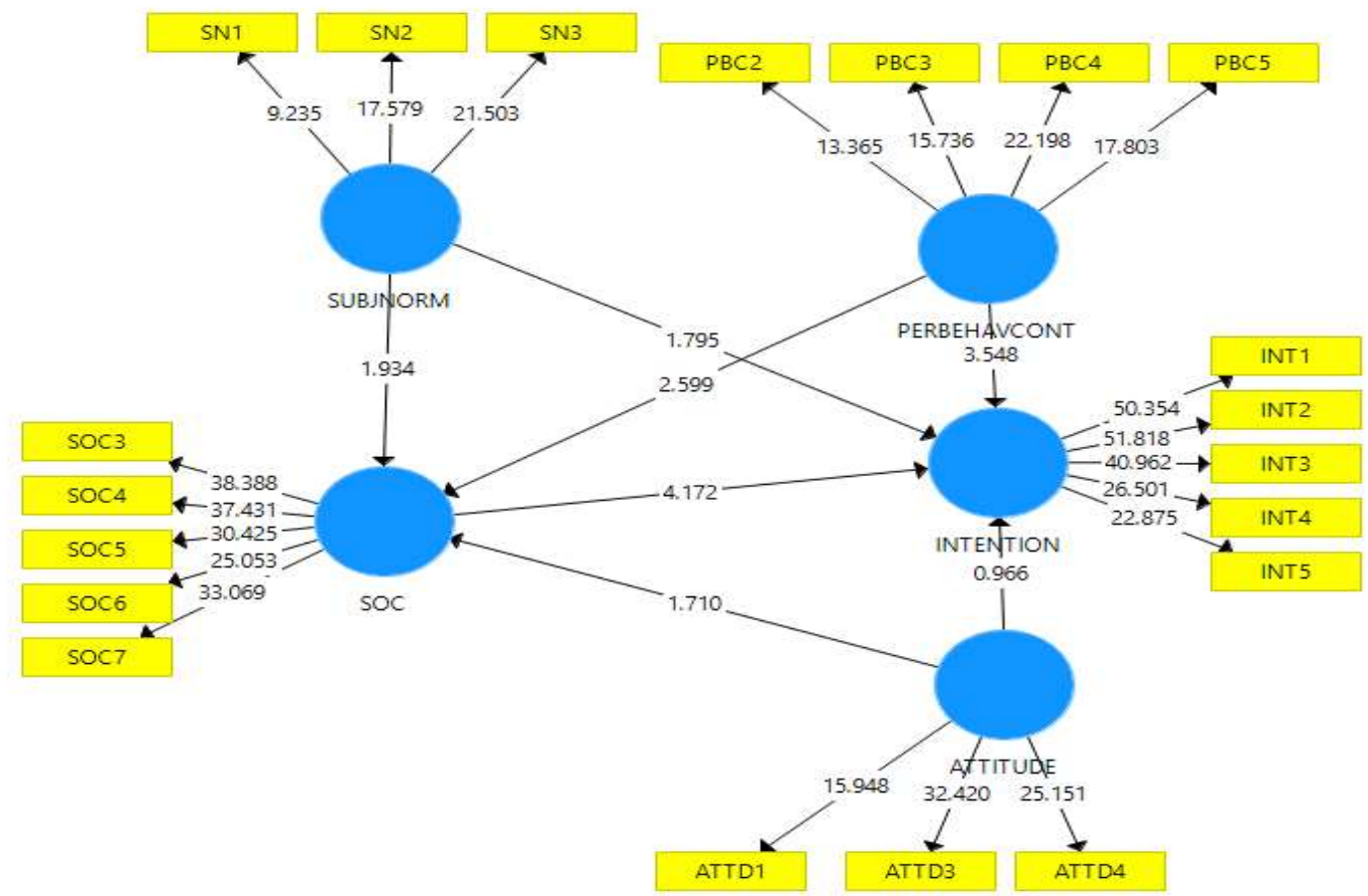

Figure 5. Structural Model: In-direct effect

Assessment of Effect Size $\left(\mathrm{f}^{2}\right)$. Effect size indicates the relative effect of a particular exogenous latent variable on an endogenous latent variable (s) by means of changes in the R-squared (Chin, 1998). It is calculated as the increase in R-squared of the latent variable to which the path is connected, relative to the latent variable's proportion of unexplained variance (Chin, 1998). Thus, the effect size could be expressed using the following formula (Cohen, 1988; Selya, Rose, Dierker, Hedeker, \& Mermelstein, 2012; Wilson, Callaghan, Ringle, \& Henseler, 2007):

Effect size $\left(\mathrm{f}^{2}\right)$ evaluation $=\underline{\mathrm{R}^{2} \text { Included }-\mathrm{R}^{2} \text { Excluded }}$

$$
1-\mathrm{R}^{2} \text { Included }
$$

According to Cohen (1988), $\mathrm{f}^{2}$ values of $0.02,0.15$ and 0.35 should be operationalized and interpreted as small, medium, and large effect sizes, respectively. Table 5 demonstrates the respective effect sizes of the latent construct of the structural model.

Table 5. Effect Size of exogenous latent constructs on endogenous construct (Intention)

\begin{tabular}{|l|c|c|}
\hline & $\mathrm{f} 2$ values & Interpretation \\
\hline ATTITUDE_- & 0.045 & Small effect \\
\hline PERCBHCONTROL & 0.256 & Medium effect \\
\hline SUBJNORM_ & 0.073 & Medium effect \\
\hline
\end{tabular}

Note: Interpretation of the Effect sizes ( $\left.\mathrm{f}^{2}\right)$ were based on Cohen's (1988) guidelines.

As shown in Table 5, the effect sizes for the attitude was 0.045 on intention can be considered as small effect since the $\mathrm{F}^{2}$ value was 0.045 . While, subjective norm, and perceived behavioral control on intention suggested a medium effect on intention to purchase cosmetics products as $\mathrm{F}^{2}$ values $=$ 0.073, and 0.256 respectively can be regarded as a medium effect (Cohen, 1988).

This part discusses the study's findings in the light of the theory of planned behavior (TPB) and Technology acceptance model (TAM) and findings of previous studies. Firstly, the level of consumer behavior exhibited among the Bruneian intention to purchase cosmetics products via the social media 
platform. Secondly, the direct effects of attitude perceived behavioral control and subjective norm on intention to purchase cosmetics products. Thirdly, the mediating effect of social media on the effect of attitude perceived behavioral control and subjective norm on intention to purchase cosmetics products are elaborated. In line with the research question and objectives to determine the level of consumer behavior exhibited among the Bruneian intention to purchase cosmetics products via social media platform were reported to exhibit higher level of consumer's subjective norm (mean 2.046 with $\mathrm{SD}=0.868$, represented $40.92 \%$ based on 5-point Likert scale); attitude (mean 2.008, $\mathrm{SD}=0.714$, represented $40.16 \%$ based on 5-point Likert scale) and Perceived behavioral control (mean 1.903 $\mathrm{SD}=0.757$, represented $38.06 \%$ based on a 5 -point Likert scale). These findings are in line with the previous studies that reported on the consumer behavioral intention to purchase products.

Direct effects of attitude, perceived behavioral control and subjective norm on intention to purchase cosmetics products.

$\mathrm{H}_{\mathrm{A} 1}$ : Attitude has a positive significant effect on consumer behavioral intention to purchase the cosmetic product in Brunei Darussalam on the platform of social media

As shown in Table 4, the hypotheses analysis between an attitude and intention to purchase the cosmetic product in Brunei Darussalam is positively significant with small effect size $\left(\mathrm{f}^{2}=0.045\right)$, $(\beta=0.241, t$-value $=1.714, \mathrm{p}=0.043)$. Hence, we accept the first hypothesis as $\mathrm{p}<.05$. On the whole, the regression result indicated the model was explained by $73.6 \%$ of the variance of the consumer intention to purchase. This finding means that the variation in the consumer intention to purchase cosmetic products in Brunei Darussalam was explained significantly by the extent of consumer attitude. The study results agreed with the previous studies that argued on the more favorable attitudes toward the behavior the consumers, the more likelihood of the consumer intention to purchased cosmetic products (Lada, et al., 2009). The link between the attitude and intention to purchase has widely been claimed in a variety of product categories and cultures, including cosmetic products (Sukato \& Elsey, 2009; Kim \& Chung, 2011). The study has shown that attitude a significant determinant of intention in a study of consumer behavior. The more the positive attitude consumers have towards purchase behavior, the stronger the consumer's intentions to perform a behavior under their control (Ajzen, 1991). Furthermore, there is a possibility that the respondents' attitude towards purchasing cosmetic products online have been affected by the people close to them as attitude towards online shopping could affect person's intention to purchase on social media platform (Korzaan, 2003).

$\mathrm{H}_{\mathrm{A} 2}$ : Subjective norm has a positive significant effect on consumer behavioral intention to purchase the cosmetic product in Brunei Darussalam on the platform of social media.

The extent of the Subjective norm was found to be positively and statistically significantly associated with consumer behavioral intention to purchase the cosmetic product with medium effect size $\left(\mathrm{f}^{2}=0.073\right),(\beta=.241, \mathrm{t}=2.501, p=.006)$. Hence, hypothesis 2 was accepted at $p<0.01$. This finding means that the variation in the consumer behavioral intention to purchase the cosmetic product was explained significantly by the extent of the subjective norm. On the whole, the regression result shows the model jointly explained $73.6 \%$ of the variance of consumer behavioral intention to purchase the cosmetic product. This finding means that the variation in consumer behavioral intention to purchase the cosmetic product was explained significantly by the extent of subjective norm. Therefore, the study has shown that subjective norm is a significant determinant of intention in a consumer behavior. The findings of the study are consistent with previous studies (Guthrie et al., 2008; Vanessa et al., 2010).

$\mathrm{H}_{\mathrm{A} 3}$ : Perceived behavioral control has a positive significant effect on consumer behavioral intention to purchase the cosmetic product in Brunei Darussalam on the platform of social media.

The extent of perceived behavioral control was found to be positively and statistically significantly associated with consumer behavioral intention to purchase the cosmetic product with medium effect size $\left(\mathrm{f}^{2}=0.256\right),(\beta=.449, \mathrm{t}=4.229, p=.000)$. Hence, hypothesis 3 was accepted at $p<0.01$. This 
finding means that the variation in the consumer behavioral intention to purchase the cosmetic product was explained significantly by the extent of the perceived behavioral control.

On the whole, the regression result shows the model jointly explained $73.6 \%$ of the variance of consumer behavioral intention to purchase the cosmetic product. This finding means that the variation in consumer behavioral intention to purchase the cosmetic product was explained significantly by the extent of perceived behavioral control. Therefore, the study has shown that perceived behavioral control a significant determinant of intention in a consumer behavior. The findings of the study are consistent with previous studies (Ajzen 1991).

Mediating effect of social media on the effect of attitude, perceived behavioral control and subjective norm on intention to purchase cosmetics products. Despite a growing body of previous studies that attest the relationship between consumer behavior (attitude, subjective norm, perceived behavioral control) and purchase intention, relatively little is known about a catalyst behind the increasing relationship especially in this period of globalization. The goal of this study was to test the mediation model with social media as the mediator variable to explain the relationship between consumer behavior (attitude, subjective norm, perceived behavior control) and intention to purchase the cosmetic product in Brunei Darussalam. To achieve this goal, we used Preacher and Hayes' (2008) bootstrapping technique of estimating indirect effects in simple mediation model to test the hypothesis:

$\mathrm{H}_{\mathrm{A} 4}$ : Social Media has a positive significant mediating effect on the consumer attitude and intention to purchase the cosmetic product in Brunei Darussalam.

$\mathrm{H}_{\mathrm{A} 5}$ : Social Media has a positive significant mediating effect on the consumer subjective norm and intention to purchase the cosmetic product in Brunei Darussalam.

$\mathrm{H}_{\mathrm{A} 6}$ : Social Media has a positive significant mediating effect on the consumer Perceived behavioral control and intention to purchase the cosmetic product in Brunei Darussalam.

The mediator analysis revealed that social media plays a significant role in the relationship between consumer behavior (attitude, subjective norm, perceived behavior control) and intention to purchase the cosmetic product in Brunei Darussalam. Specifically, the present study confirms previous research (Lada, et al., 2009; Sukato \& Elsey, 2009) showing attitude, subjective norm, perceived behavior control plays a significant role in explaining intention to purchase (Kim \& Chung, 2011). A plausible explanation for this finding is that social media is the fundamental reason why consumer behavioral attitude, subjective norm, perceived behavior control predict consumer intention to purchase the cosmetic product. This line of argument is consistent with tam (Korzaan, 2003; Guthrie et al., 2008; Vanessa et al., 2010).

The findings regarding mediating effects represent the main contributions of this research, possible explanations of the mediating effect of social media could be explained from theoretical perspectives rather than prior empirical studies. Thus, Theory of Planned Behavior (TPB) Ajzen (1991), and Technology acceptance model (TAM) Davis (1986); Davis (1989) argued that Technology acceptance model (TAM), have strong behavioral elements, assume that when someone forms an intention to act, that they will be free to act without limitation. In practice constraints such as limited ability, time, environmental or organizational limits, and unconscious habits will limit the freedom to act. TAM is an information systems theory that models how users come to accept and use a technology. The model suggests that when users are presented with a new technology, a number of factors influence their decision.

Also, the previous study used TAM to argue on the major factor that influences consumers to use the social network as a platform for assisting their buying decision (Di Pietro \& Pantano, 2012). The study found that factors that motivate individuals to pay attention to the products promoted on Facebook include the fun that Facebook provided, as well as the opportunity it provides users to ask for suggestions in an easy and entertaining way. "Facebook promotes a consumer to consumer approach, exploited by consumers to share experiences and create a common knowledge on products 
and service; on the other, it provides managers a direct channel for communicating with clients through a business to consumer approach (Di Pietro \& Pantano, 2012).

Therefore, retailers need to be educated on consumer's attitudes when it comes to social media marketing and a deeper understanding of how consumers perceive social marketing will help ensure effective marketing strategies. Previous studies argued that over 11 million consumers use more than $70 \%$ of many social media to do their shopping and purchasing of different products and services on the platform of social media (Miller \& Lammas, 2010). The most popular social media platform that is mostly used by the consumers are Facebook, Twitter, and Instagram. Therefore, based on the review on previous studies on the perceived social media platform, consumer's behavior and purchase intention, the present mediating results appear to be congruent with TPB and TAM (Di Pietro and Pantano, 2012).

Theoretical Implications. First, by examining the influence of consumer attitude on purchase intention provided an empirical confirmation of the effect of attitude on intention to purchase the cosmetic product (Celik, 2008; George, 2002, 2004; Chai \& Pavlou, 2004). The results are in line with the assertion that consumer behavioral attitude factor is important in understanding consumer purchase intention because attitude towards purchasing cosmetic products online have been affected by the people close to them as attitude towards online shopping could affect person's intention to purchase on social media platform (Korzaan, 2003). Second, in relation to subjective norm factors, present research examined the relative influence of subjective norms on consumer behavior. Subjective norm is a significant determinant of intention in a consumer behavior (Guthrie et al., 2008; Vanessa et al., 2010). There is a positive correlation between subjective norms on behavioral intention in the context of behavior therefore it is reasonable to argue that Subjective norm has significant influence on behavioral intention in the context of behavior related to skin management, skincare products (Hillhouse et al., 2000; Souiden \& Diagne, 2009, Sukato \& Elsey, 2009). Kim and Chung (2011) support the decision of purchasing skincare product as it produces a positive correlation between the perception of subjective norm and behavioral intention. Third, the findings of the study revealed that perceived behavioral control strongly affect consumer intention to purchase a cosmetic product on the social media platform in Brunei Darussalam. The findings of the study are consistent with previous studies (Ajzen 1991). Fourthly, the findings of this study underscore the importance of social media role in the relationship between consumer attitude, subjective norm, and perceived behavioral control on a consumer behavioral intention to purchase the cosmetic product in Brunei Darussalam. The findings of the study are consistent with previous studies (Ajzen 1991).

Practical Implications. The results of the current study appear to have important implications for the organizations and managers. First, the finding that Attitude, Subjective norm and Perceived behavioral control was positively related to consumer intention to purchase demonstrates that attitude is formed as a result of experience and learning outcomes and these factors did affect the consumer buying behavior (Kotler and Keller, 2009, 210). Noel $(2009,99)$ notes that "some attitudes may also be formed based on research; a consumer may read reviews about an interesting product and discuss it with his or her friends and form an attitude based on the acquired information. Attitudes may also be formed through feelings. Second, the results suggest that perceptions of the subjective norm are important to analyzing consumer behavior in terms of pricing. Consumers often create a standard price of a product, other meaning, as regarded as a fair price for a certain type of product. This standard price that a consumer expects is then used as a basis for comparing the prices of other brands. According to the study conducted by Oakley (2009), women wearing cosmetic feel more confident due to these brands advertise them as providing the confidence that needs to be shown in the society. Methodological Implications. The present study has a number of methodological implications. The most explicit of these methodological implications lie in the adoption of PLS path modelling (Wold, 1974, 1985) using Smart PLS 2.0 M3 software (Ringle et al., 2005) to test the theoretical model. Empirically, PLS path modelling has provided insights that are not available through other analysis methods typically used in organizational research (e.g., regression analysis, analysis of variance and 
chi-square analysis), which can only analyses one layer of a relationship between independent and dependent variables at a time. Specifically, the PLS path modelling enables the estimation of multiple layers of the relationships between constructs (structural model) and relationships between indicators and their corresponding latent constructs (measurement model) simultaneously (Chin et al., 2003; Duarte \& Raposo, 2010; Gerlach et al., 1979; Lohmöller, 1989). Another methodological implication of this study is on the use of PLS approach to Enhance the construct validity of key measures through the use of measurement model approaches to examine the mediating effect of social media on the relationship between consumer behavior (attitude, subjective norm, perceived behavior control) and intention to purchase cosmetic product in Brunei Darussalam. Among the few empirical studies that use PLS approach to estimate mediating effect include the works of Abubakar, Chauhan \& Kura, 2015; Lam, Chen \& Takeuchi, 2009).

\section{Conclusion}

The objectives of this research project have been met in which firstly to critically review literature related to the impact of social media on the buying behavior of cosmetic products. It has proven that the social media does give an impact in changing the respondent's behavior from the factors that have influence and motivates them to make the decision to buy the products. It is not just because of their attitudes but also their intention to purchase will determine their buying behavior.

The consumer's perception of online shopping varies from individual to individual and the perception is limited to a certain extent with the availability of the proper connectivity and the exposure to the online shopping. The study clearly states the social media marketing leads the cosmetics products to reach the customers of different age group, different lifestyle, based on their salary (to measure their affordability) and their skin type. The study highlights the fact that the youngsters between the ages of 26-32 are mostly poised to use the online shopping. Furthermore, the important of the products and the influence of a person around them will give an impact on their buying behavior in making a decision. The cosmetic products quality and price also one of the important factors that will influence the consumers to buy cosmetic products in social media. From friends and acquaintances, reviews or previous consumers comments also will change the consumer behavior unexpectedly.

Based on the findings, the results stated that the consumer buying behavior on cosmetic products through social media can be predicted by attitude, subjective norm and perceived behavioral control. It has found that those three factors have significant and positive relationship effects on buying behavior. Perceived behavioral control has the most significant influence or positively related to consumer's buying behavior on cosmetic products which means that the perceived behavioral control has the strongest predictor of consumer behavior, the attitude, and subjective norm. Therefore, we can positively answer or accept the attitude, perceived behavioral control and subjective norm has a significant and positive impact on the consumer buying behavior on cosmetic products in Brunei Darussalam. Also, social media can have an impact in influencing consumer behavior (attitude, subjective norm, perceived behavior control) and intention to purchase the cosmetic product in Brunei Darussalam.

\section{References}

Ajzen, (1991). The Theory of Planned Behavior," Organizational behavior and human decision processes, 50, (1991).

Ajzen, I. (1985). From intentions to actions: a theory of planned behavior", in Kuhl, J., Beckmann, J. (Eds), Action Control: From Cognition to Behavior, Springer-Verlag, New York, NY.11-39.

Ajzen, I., Fishbein, M., (1980). The theory of planned behavior. Organ. Behav. Hum. Decision Process. 50, 179- 211.

Ackerberg, D.A. (2001). Empirically distinguishing informative and prestige effects of advertising. Rand Journal of Economics, 32, 316-333

Aiti, (2016). Brunei Darussalam Household ICT Survey Report 2016, Available at 
https://www.aiti.gov.bn/downloadables/Downloadables\%20Library/Household\%20ICT\%20 Survey\%2020 16\%20Report.pdf.pdf [Assessed on 21 Apr 2018]

Bachleda, C., Fakhar, A., and Hlimi, L., (2012). Sunscreen purchase intention amongst young Moroccan adults, International Journal of Academic Research in Business and Social Sciences, Vol.2, No.5, pp132-150 [4] Bredhal, L.,

Bandura, A. (2007). Much ado over the faulty conception of perceived self-efficacy grounded in faulty experimentation. Journal of Social and Clinical Psychology, 26(6), 641-758. [See Cahill et al.'s problematic piece]

Behavioral Change Model (2016). The Theory of Planned Behavior. Available at http://sphweb.bumc.bu.edu/otlt/MPH Modules/SB/BehavioralChangeTheories/BehavioralChangeTheories3.html [Assessed on 15 March 2018]

Celik, H. (2008). What determines the Turkish customer's acceptance of internet banking? International Journal of Bank Marketing, 26, 5, 353- 369.

D. Hoffman and T. Novak (2000). "How to acquire customers on the web," Harvard Business Review, 78, 3 (2000) Actual Online Shopping Behavior among... (PDF Download Available). Available from: https://www.researchgate.net/publication/272769064 Actual Online Shopping Behavior a mong Jordanian Customers [accessed Apr 16 2018].

Desai, K. (2014), 'A Study On Consumer Buying Behavior Of Cosmetic Products In Kolhapur', Reviews Of Literature Volume 1, Issue 10 / May 2014, ISSN: 2347- 2723.

Deighton, J., Henderson, C.M., Neslin, S.A. (1994). The effect of advertising on brand switching and repeat purchasing', Journal of Marketing Research, p.p. 28- 43.

Erdem, T., Keane, M. (1996), Decision-making under uncertainty: Capturing dynamic brand choice processes in turbulent consumer goods markets. Marketing Science, 15, 1-20.

Eagely, A H., \& Chaiken, S (1995). Attitude strength structure, and resistance to change. In R.

E petty \& J. A. Krosnick (Eds.), Attitude strength: Antecedent and consequences (pp. 413-32). Mahwah, NJ: Erlbaum.

Evans, M., Jamal, A. \& Foxall, G. (2006). Consumer Behavior. John Wiley \& Sons Ltd. West Sussex.

Evans, M., Moutinho, L. \& Van Raaij, W. F. (1996). Applied Consumer Behavior. Addison-Wesley Publishing Ltd. Cornwall.

Guthrie, F. M., Kim, H-S., \& Jung, J., (2008). The effects of facial image and cosmetic usage on perceptions of brand personality. Journal of Fashion Marketing and Management, 12(2): 164181.

Hair, J. Wolfinbarger, M. \& Money, A. (2011). Essentials of Business Research Methods. 2nd ed. New York: M.E. Sharpe. P34-56.

Hsiao, M.-H. 2009. Shopping mode choice: Physical store shopping versus e-shopping.

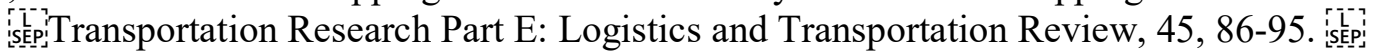

Hillhouse, J., Turrisi, R., \& Kastner, M., (2000). Modeling tanning salon behavioral tendencies using appearance motivation, self-monitoring and the theory of planned behavior. Health Education Research, 15(4): 405-414

Vermeir, I \& W. Verbeke (2008). "Sustainable food consumption among young adults in Belgium: Theory of planned behavior and the role of confidence and values," Ecological Economics, 64, (2008).

Ilham Sentosa, \& Nik Kamariah Nik Mat (2012) "Examining a Theory of Planned Behavior (TPB) And Technology Acceptance Model (Tam) In Internet Purchasing Using Structural Equation Modeling [SEP." www.researchersworld.com. III, 2 (2)

Jamal, A., Khan, M. S., \& Stamatia, M. T., (2012). Information cues roles in product evaluations: the case of the UK cosmetics market. Journal of Strategic Marketing, 20(3): 249-265. 
Joy A, \& Venkatesh A (1994). Postmodernism, feminism, and the body: The visible and the invisible in consumer research. Int. J. Res. Mark., 11: 333-357.

Krishnamurthi, L., \& Raj, S.P. (1985), 'The effect of advertising on consumer price sensitivity', Journal of Marketing Research, 22, p.p. 119-129.

Kim, Y. \& Han, H. (2010). Intention to pay conventional-hotel prices at a green hotel a modification of the theory of planned behavior. Journal of Sustainable Tourism, 18(8), 997-1014.

Kim, H. Y. \& Chung, J.-E., (2011). Consumer purchase intention for organic personal care products. Journal of Consumer Marketing, 28(1), 40-47

Kumar, S., (2005). Exploratory analysis of global cosmetic industry: major players, technology, and market trends. Technovation, 25(11): 1263-1272.

Kotler, P. \& Keller, K. L. (2009). Marketing Management. Pearson International Edition. 13th edition. Pearson Education Inc. Upper Saddle River.

Kim, Y. H., \& Chung, J. E. (2011). Consumer purchase intention for organic personal care products. Journal of Consumer Marketing, 28(1), 40-47

Liou, D., and Contento, I.R., (2001). "Usefulness of psychology theory variables on explaining fatrelated dietary behavior in Chinese Americans": Association with a degree of acculturation. Journal of Nutrition Education, 33(6):322-331.

Levin, A. M., Levin, I. P. \& Weller, J. A. (2005). A multi-attribute analysis of preferences for online and offline shopping: differences across products, consumers, and shopping stages. Journal of Electronic Commerce

Research, 6, 281-290.

Mulhern, R., Fieldman, G., Hussey, T., Leveque, J. \& Pineau, P. (2003). "Do cosmetics enhance Caucasian female facial attractiveness? "International Journal of Cosmetic Science, 25(4), 199205.

Noel, H. 2009. "Consumer Behavior". AVA Publishing SA. Lausanne.

Nash R, Fieldman G, Hussey T, Leveque JL\& Pineau P (2006). Cosmetics: They Influence More Than Caucasian Female Facial Attractiveness. Journal of Applied SocioPsychology. 36 (2): 493-504.

Oakley, H. (2009), 'An Evaluation of Current Techniques in Cosmetic Advertising and an assessment of their effectiveness on the contemporary consumer'.

Pavlou, P. A., \& Chai, L. (2002), "What Drives Electronic Commerce across cultures? A CrossCultural Empirical Investigation of the Theory of Planned Behavior", Journal of Electronic Commerce Research, Vol. 3, No. 4, pp. 240-253.

R. Dholakia \& O.Uusitalo (2002). "Switching to electronic stores: consumer characteristics and the perception of shopping benefits," International Journal of Retail and Distribution Management, 30, 10 (2002). Actual Online Shopping Behavior among... (PDF Download Available). Available

from: https://www.researchgate.net/publication/272769064_Actual_Online_Shopping_Behavior_a mong_Jordanian Customers [accessed Apr 16 2018].

Roy Morgan Research (2016). "You beauty! Buying cosmetics and skincare online becoming popular (2016) http://www.roymorgan.com/findings/6832-buying-cosmetics-skincare-onlinebecoming-more-popular201606010102 [Accessed March 10, 2018]

Reeves Roose (1961), 'Reality in Advertising', Alfred Knopf Inc., New York.

Souiden, N., \& Diagne, M., (2009). Canadian and French men's consumption of cosmetics: a comparison of their attitudes and motivations. Journal of Consumer Marketing, 26(2): 97-109.

Sukato, N., \& Elsey, B., (2009). A model of male consumer behavior in buying skin care products in Thailand. ABAC Journal, 29(1): 39-52.

Solomon, M. R. (2007). Consumer Behavior - Buying, Having and Being. 7th edition. Pearson Education Inc. Upper Saddle River. 
Toomey, A. C. \& Wysocki, A. F. Distinguishing between Traditional and Online Retailing: Evaluating E-commerce with Respect to the Food System1.

Venkatesh, Morris \& Ackerman, (2000) Organizational Behavior and Human Decision Processes Vol. 83, No.

1, September, pp. 33-60, 2000.

Vanessa, A-I., Hartmann, P., Diehl, S., \& Terlutter R., (2010). Women satisfaction with cosmetic brands: The role of dissatisfaction and hedonic brand benefits. African Journal of Business Management, 5(3): 792-802.

Verbecke \& Vackier, (2005). "Individual determinants of fish consumption: application of the theory of planned behavior".67-82.

Zephora, (2018). "The Top Valuable Facebook statistics" https://zephoria.com/top-15-valuablefacebook-statistics/ [Accessed April 17, 2018] 